\title{
Vindicación y elogio de la retórica deliberativa: glosas de Aristóteles*
}

Vindication and praise of deliberative rhetoric:

\author{
Glossing Aristotle
}

\author{
LUIS VEGA REÑÓN
}

UNED, Madrid

\begin{abstract}
Resumen. Hoy estamos asistiendo a un creciente interés por la retórica argumentativa debido a su estrecha relación con el discurso público. Tienen especial relieve dos puntos a este respecto: 1, la contribución de la retórica a la revisión crítica de los programas en curso de la llamada "democracia deliberativa"; 2, la lectura de la Retórica de Aristóteles en la línea de estos propósitos críticos. Mi artículo se propone desarrollar este segundo punto a través de un examen de la concepción aristotélica de la retórica y de su vindicación de la deliberación pública.
\end{abstract}

Palabras clave: Aristóteles, Retórica, deliberación, retórica deliberativa.
ABSTRACT. Today we are witnessing the increasing interest in the argumentative rhetoric because of its close relationship with the public discourse. Two points have been highlighted in this regard: 1 , the contribution of rhetoric to the critical revision of the ongoing programs of the so-called "deliberative democracy"; 2, the reading of Aristotle's Rhetoric in line with these critical purposes. The aim of my paper is to develop this second point through an examination of the Aristotelian conception of rhetoric and his vindication of public deliberation.

Key words: Aristotle, Rhetoric, deliberation, deliberative rhetoric.

Para hablar de retórica y de deliberación nunca está de más volver a las fuentes clásicas, en especial a Aristóteles. Pero ahora es recomendable no solo por la razón genérica de tratarse de un autor clásico -alguien cuyos textos siempre pueden decir o sugerir algo de interés y de provecho-, sino por una razón concreta y acorde con los signos de nuestro tiempo. Uno de los legados de la $2^{\mathrm{a}}$ mitad del siglo XX ha sido la constitución de la retórica como una nueva o renovada disciplina dentro del campo de la argumentación, más allá de la tradición escolar que la reducía a la oratoria o a un género ornamental literario o estilístico. Pues bien, hoy estamos asistiendo a un creciente interés por esta re-

\footnotetext{
* Trabajo realizado en el marco del proyecto FFI2011-23125, financiado por el Ministerio de Ciencia e Innovación y el Ministerio de Economía y Competitividad.
} 
tórica argumentativa debido a su estrecha relación con el discurso público. $\mathrm{Si}$ recordamos los orígenes de la retórica en la cultura grecolatina como una forma paradigmática de discurso público, podemos hablar de un renacimiento actual en este sentido. Se han señalado dos motivos al respecto: 1) La influencia de la retórica en la revisión de programas de la llamada "democracia deliberativa" que, desde los años 1980-90, se ofrecen como alternativa a los anteriores programas democráticos, liberales o republicanos, en el campo de la filosofía política. 2) La recuperación de la Retórica aristotélica a esos efectos críticos, en la medida en que representa un desafío o, cuando menos, invita a la discusión de algunos aspectos y supuestos de esa pretendida democracia deliberativa ${ }^{1}$.

Como antes decía, la tradición clásica de la retórica mantuvo en sus orígenes estrechas relaciones con el discurso público, en general, y con la deliberación política en particular. Pero de ahí no se sigue que siempre se hayan llevado bien, ni mucho menos. En nuestros días, las relaciones de la retórica con la democracia deliberativa se podrían resumir con arreglo a estas tres variantes principales:

A/ Hostilidad o exclusión entre una y otra. Bien por motivos de orden epistémico, como la contraposición entre las emociones y pasiones, o las alegaciones personales, propias todas ellas de la retórica, y las razones y ponderaciones, propias de la deliberación; amén del supuesto de que solo una Razón impersonal y universal puede reconocer y legitimar los argumentos y las decisiones en juego. O también por motivos de orden ético, como el respeto a la autonomía de los agentes deliberativos, frente a la retórica que los induce a determinadas creencias o disposiciones condicionando o coartando su lucidez y su libertad. Por lo demás, unos y otros motivos cuentan con grandes valedores en filosofía: así, en los motivos éticos hay ecos de Kant; en los epistémicos, hay ecos de Habermas; al fondo se dejan ver las luces o las sombras -según se mire- de Platón.

B/ Vecindad y subordinación de la retórica: sirve como un aderezo expresivo o como un complemento emocional que acompaña al discurso argumentativo e incluso podría eventualmente sustituirlo para mover al auditorio a prestar atención y dejarse convencer, para crear ambientes propicios y facilitar acuerdos, etc. Como esto supone ciertos conocimientos y recursos técnicos, a la retórica se le puede reconocer el estatuto de una disciplina auxiliar

${ }^{1}$ Vid. el informe de Bryan Garsten (2011) “The rhetoric revival in political theory”. Por cierto, el caso de la propia revista, Political Theory, es ilustrativo. Entre 1973 y 2000, apenas publicó cuatro artículos alusivos a las relaciones entre el programa deliberativo y la retórica; entre 2001 y 2011 lleva publicados más de diez artículos de reconocido relieve e influencia, que además hacen referencia a la contribución fundacional de la Retórica aristotélica. 
específica. Se trata de una postura más bien convencional y se halla relativamente extendida en medios académicos y profesionales.

$\mathrm{C} /$ La retórica conforma el discurso deliberativo como una dimensión constitutiva. No solo obra a efectos de presentación o exposición (imágenes, valoraciones, historias, etc.), sino como discurso característico de una interacción pública deliberativa, en parte afín a la contemplada en la Retórica de Aristóteles. Más aún, a partir de ahí cabe postular alternativas críticas frente a una concepción normativa y autónoma de la lógica del dar/pedir razón que suponga restricciones tanto de los discursos convalidables, como de la gente admisible o siquiera "visible" en el proceso público de deliberación ${ }^{2}$. En esta perspectiva, la reinterpretación de la Retórica de Aristóteles no es una simple cuestión de exégesis o de culto académico, sino una fuente de inspiración y lucidez para lidiar con nuestros problemas: es, en suma, lo que se espera de un clásico.

\section{Antecedentes}

Como es sabido, el desarrollo socio-político en la Atenas de los ss. VI y V a.n.e. alumbra un nuevo régimen democrático con el ascenso del demos como un agente socio-político relativamente autónomo, dispuesto a deliberar y decidir colectivamente sobre asuntos de interés común. Así aparece la retórica deliberativa como modo de intervenir en el discurso público y, a través de él, en la vida política. De su aparición da fe Tucídides en la Historia de la guerra del Peloponeso, por ejemplo a través del Discurso fúnebre de Pericles (II.35-46), que elogia la participación activa y discursivo-reflexiva de los atenienses en los asuntos públicos; o en el debate sobre la suerte de Mitilene (III.38-42), donde Diódoto hace valer las ventajas de la deliberación previa y de la decisión ponderada frente a la actuación inmediata y violenta que pretende Cleón. Pero este género de discurso público también provoca reacciones adversas, tanto críticas ideológicas como invectivas satíricas ${ }^{3}$. Du-

\footnotetext{
${ }^{2}$ Pueden verse consideraciones del tipo A en Benhabib (1996) o en Cohen (1997); sobre la línea ética y epistémica de Kant y Habermas, cf. 0’Neill (2002), Abizadeh (2007). Consideraciones del tipo B se encuentran por ejemplo en Gutmann \& Thompson (1996), Chambers (2009), Dryzek (2001, 2010). Y, en fin, del tipo C en Young (1996), Abizadeh (2002), Yack (2006) o en el ya citado Garsten (2011). Hay un punto de divergencia crucial entre las dos variantes primeras y la tercera: A y $\mathbf{B}$ descansan de manera tácita o expresa en la división del discurso en pares de opuestos: razón vs. pasión, abstracto vs. concreto, universal vs. particular; convicción racional vs. persuasión, mientras que $\mathbf{C}$ busca su integración.

${ }^{3}$ Cf. la críticas de Demódoco y Sísifo, en Platón, Diálogos VII (Dudosos, Apócrifos, Cartas). Madrid: Gredos, 1992. El satírico clásico es Aristófanes (vid. e.g. Los caballeros, La asamblea de las mujeres). Los reparos consisten sustancialmente en negar la legitimidad discursiva y cognitiva de la deliberación pública o la capacidad de una multitud abigarrada para su ejercicio responsable.
} 
rante los ss. V-IV, algunos intelectuales como los sofistas y sus competidores van tomando conciencia de esa forma deliberativa de actuación e intervención en los asuntos públicos, y de los problemas y dificultades que genera. Se plantean, especialmente, problemas de capacidad y de acreditación; por ejemplo, en una asamblea, ¿cómo es posible tomar decisiones racionales, oportunas y efectivas entre tanta gente, gente para colmo indocumentada?

Es instructiva a este respecto la respuesta de Protágoras a una cuestión de este tipo que recoge Platón en los términos del mito de Prometeo-Hermes (Protágoras 320d-322d). Allí Sócrates pregunta: ¿Por qué se recurre a los expertos en cuestiones técnicas, e.g. de construcción o navales, pero no cuando se trata del gobierno de la pólis? Responde Protágoras: «¿Preferís que lo demuestre [epideíxo] relatando un mito o mediante un discurso razonado?» (320c). Con la aquiescencia de sus interlocutores, Protágoras opta por la demostración a través del mito 4 . Según el mito, Zeus encarga a Prometeo la distribución de cualidades entre los seres vivos. Prometeo delega la tarea en un poco previsor Epimeteo que se ve con las manos vacías cuando llega a los humanos. En compensación de sus carencias naturales, Prometeo les entrega el fuego y las técnicas. Pero los hombres vienen a caer entonces en disputas y luchas por intereses enfrentados que hacen imposible la convivencia. Para asegurarse de que al menos sobrevivan, Zeus confía a Hermes un nuevo reparto general e igualitario del sentido de la justicia [diké] y de la dignidad o vergüenza [aidós] entre los humanos. Pues frente a la anterior distribución desigual de cualidades y recursos, Zeus repara en que los nuevos dones se han de repartir entre todos los seres humanos porque si solo participaran de ellos unos pocos, como ocurre con las demás artes especializadas, nunca llegaría a haber ciudades $(322 \mathrm{c}-\mathrm{d})$.

Sigamos con Platón pues de algunos diálogos cabe extraer un sumario de los reparos principales a la retórica deliberativa. Pueden agruparse en estos dos frentes: la retórica y la deliberación pública.

\section{A/ Contra la retórica}

La retórica es a la justicia lo que el cocinar a la medicina (Gorgias 465c), o también es respecto del alma lo que el cocinar respecto del cuerpo (465d). En

${ }^{4}$ Importa reparar en que esta opción es un recurso típicamente retórico a una "historia" o una narratio. Así, a la vez que cumple sus funciones expresivas, simbólicas o alegóricas, también pretende servir a los efectos ilustrativos, esto es probatorios y suasorios, de una perspectiva plausible; en suma, quiere ser una respuesta pertinente y efectiva a la cuestión planteada por Sócrates. 
suma, la retórica viene a ser antístrofa, correlativa de la cocina (ibd.): las dos descansan en la mera experiencia de donde obtienen rutinas o recetas para producir agrado y placer (Gorgias 462e), pero una y otra están lejos de constituir artes o ciencias ${ }^{5}$. En otras palabras, los retóricos no tienen un objeto susceptible de análisis y estudio, ni cuentan con criterios de eficiencia técnica. Su pretensión distintiva es lograr la gratificación y la aprobación del auditorio. Así pues, la retórica no es un arte. Es una simple práctica, sea demagógica o practicada para peor cuando se trata de persuadir al demos ignorante sin instruirlo, o sea psicagógica, practicada para mejor, cuando se trata de conducir al alma hacia la contemplación de las ideas. Por otro lado, quienes presumen de pericia discursiva (los rhetores y los sofistas) supeditan el interés por la verdad o por lo justo y lo injusto a otros intereses y consideraciones; en todo caso, les basta con ocuparse de lo verosímil, aunque sea engañoso (Fedro 272d).

\section{B/ Contra la deliberación pública}

La pretendida deliberación constituye una mezcla degenerativa de auditorios incapaces de discernir la verdad y proclives a dejarse engañar, con oradores celosos de oscuros intereses y dados a halagar las pasiones del populacho. Cuando menos viola un supuesto de la buena deliberación política: el conocimiento verdadero; un saber, por cierto, solo accesible a los expertos, a los filósofos en este caso, pero no a la ciudadanía en general, pues es imposible que la gente en su conjunto sea filósofa (República, 494a). Lejos de atenerse a esta condición epistémica, la deliberación pública procede a determinar lo debido (lo honesto, lo justo, lo piadoso) por acuerdos mayoritarios (Teeteto 172b), a través de un discurso puramente suasorio y plausible (es decir, sin pruebas efectivas como las del geómetra, ibd. 162e), y por parte de una muchedumbre presa de sus pasiones y atada a sus dispares intereses, porque, en definitiva, la multitud está incapacitada no solo para un conocimiento especializado sino para el uso lúcido y reflexivo de la razón.

Platón adopta así una perspectiva diametralmente opuesta a la abierta por el mito de Protágoras. Aristóteles, como veremos, tratará luego de responder a ambos tipos de reparos, los dirigidos contra la retórica y los dirigidos contra la deliberación pública. Pero ahora se puede adelantar su respuesta a estos segundos a través de una declaración capital de la Política, en la que expone su concepción del lenguaje o del discurso [lógos] como el medio característico de comunicación, de entendimiento y de juicio del ser humano en calidad de ani-

${ }^{5}$ Platón no aprobaría nuestros cursos universitarios de gastronomía ni, desde luego, una cátedra como la "Ferrán Adriá" de la Universidad Camilo José Cela. 
mal social. Este texto declara a mi juicio una base de la justificación aristotélica de la retórica y de la deliberación común: «El hombre es por naturaleza un animal social [politicòn zôon] <...> La razón por la que el hombre es un animal social, más que la abeja o cualquier animal gregario, es evidente: la naturaleza, como solemos decir, nada hace en vano y el hombre es el único animal que tiene lógos. La voz es signo de dolor y placer, y por eso la tienen también los demás animales pues su naturaleza les permite sentir dolor y placer e indicárselo unos a otros. Pero el lógos es para manifestar lo conveniente y lo perjudicial, lo justo y lo injusto, y es propio y exclusivo del hombre, frente a los demás animales, tener el sentido de lo bueno y lo malo, lo justo y lo injusto, y demás por el estilo, y la comunidad de estas cosas es lo que constituye la ciudad y la casa» (Política I.1-2, 12532a -18). Por otro lado, «la ciudad es por naturaleza anterior a la casa y a cada uno de nosotros, porque el todo es anterior necesariamente a la parte. $<\ldots>$ Es evidente que la ciudad es por naturaleza anterior al individuo, porque si el individuo separado no se basta a sí mismo, será semejante a las demás partes en relación con el todo, y el que no pueda vivir en sociedad o no necesite nada por su propia suficiencia, no es miembro de la ciudad sino una bestia o un dios» (1253 $\left.{ }^{\mathrm{a}} 19-29\right)$. Luego solo las bestias o los dioses serían seres incapacitados o ajenos por naturaleza a la deliberación común. Parece una versión desmitificada del Protágoras.

Ahora bien, la reivindicación aristotélica de la deliberación pública discurre a través de su acreditación de la retórica como arte y, específicamente, en los términos de la retórica deliberativa. Glosaré brevemente algunas de sus contribuciones al respecto.

\section{Las contribuciones de la Retórica aristotélica}

Sabido es que la Retórica cuenta, para empezar, con ciertos términos especializados que suelen estimarse sintomáticos de la constitución de la retórica como una disciplina específica. A Aristóteles se le atribuye, en particular, la conversión de algunos términos relativos a la deliberación conjunta y al discurso en la asamblea, en particular symboulé y demegoría, en términos técnicos (Timmerman \& Schiappa 2010). Pero mayor relevancia tiene la vindicación de la retórica como un arte de pleno derecho. Conviene precisar antes que nada que, según Aristóteles, su propósito no consiste en persuadir ni, menos aún, en seducir, sino en considerar teóricamente los medios de generar convicción más pertinentes según sea el caso particular planteado (Retórica I 1.1, 1355 10 10-12, 25-6). Al ser un arte, consiste en un saber hacer fundado racionalmente en conocimientos verdaderos (Ética Nicomáquea, 6.4, 1149ª1-22), y por tanto capaz 
de explicar su proceder y de justificar sus resultados. La Retórica ofrece, en este sentido, dos caracterizaciones expresas.

Por una parte, la retórica es antístrofa de la dialéctica (Retórica I 1.1, $1354^{\mathrm{a}} 1$ ). Las versiones e interpretaciones de este calificativo se han multiplicado con el tiempo. En sustancia denota una contrapartida o correlato de la dialéctica, un arte parejo. La expresión tiene además una connotación vindicativa: recordemos que Sócrates había calificado la retórica como antístrofa del cocinar (Gorgias 465d); entonces, ¿no cabe sobreentender en su uso aristotélico una réplica implícita a Platón, gran defensor de los poderes discursivos y noéticos de la dialéctica? Sea como fuere, pueden cifrarse las similitudes o correspondencias de la retórica con la dialéctica en las cuatro siguientes:

(i) No cuenta con un campo de referencia o unos objetos propios, sino que es aplicable a cualquier asunto, $\left(1.11354^{\mathrm{a}} 2-4,1.61355^{\mathrm{b}} 8-9\right)$, y por lo tanto no es una ciencia, sino un arte o una disciplina, práctica y productiva por más señas $\left(4.11359^{\mathrm{b}} 12-16\right)$.

(ii) Tiene que ver con el discurso y puede proporcionar pruebas y argumentos razonables y persuasivos (2.2 $1355^{\text {b }} 35$ ss., y $2.31356^{\text {a } 20-34) . ~}$

(iii) Trata con lo plausible y lo verosímil (1.4 1355 15-18, 27-29), acerca de cuestiones cuya resolución puede ser o considerarse de dos maneras (2.5 1357 5-6), así que demandan o al menos admiten debate, y discurre por referencia a lugares comunes (tópicos) y opiniones más o menos acreditadas (éndoxa), i.e. más o menos dignas de crédito en razón de la cantidad y la calidad de la fuente.

(iv) Dispone de cierta capacidad de discriminación entre buenos o genuinos y malos o aparentes usos de los recursos de la disciplina, similar a la competencia de la dialéctica con respecto a las refutaciones efectivas o genuinas y las aparentes o sofísticas.

Pero estas similitudes no ocultan sus diferencias. Una diferencia básica estriba en que el dominio de la retórica es el discurso público en la tradición del rhetor no solo como orador más o menos elocuente, sino como portavoz o agente discursivo en asambleas acerca de asuntos de interés común para el colectivo de la ciudad. Según esto, bien se puede decir que la retórica es al discurso público lo que la dialéctica es al discurso digamos "particular" o "privado" en este contexto, sea monológico, cuando uno argumenta consigo mismo, o sea dialógico, cuando un agente discursivo discute con otro según el procedimiento normalizado en los Tópicos $^{6}$. La referencia al discurso público

${ }^{6}$ Un estudio de la famosa correlación de la retórica con la dialéctica planteada por Aristóteles en la Retórica, y de sus proyecciones sobre los Tópicos, puede verse en Jacques Brunschwig (1996). 
sitúa la práctica de la retórica, como ya sabemos, en el ejercicio de la política.

Pues bien, esta conexión es la que corresponde a la segunda caracterización formulada por Aristóteles donde la retórica viene a ser «un vástago de la dialéctica y de aquel saber práctico sobre los caracteres [êthe] al que es justo denominar política» (2.3 1356²6-27). En términos modernos diríamos entonces que la retórica también es una especie de hijuela de la dialéctica y de una suerte de "política-ética" o si se quiere "poli(é)tica", aunque este término ya tenga otro sentido en nuestra filosofía política ${ }^{7}$. Aristóteles no deja de insistir en esta constitución compleja que se desprende de su doble perspectiva: «Pues es cierto lo que antes hemos tenido ya ocasión de decir acerca de que la retórica se compone, por un lado, de un saber analítico y, por otro lado, político que se refiere a los caracteres; y acerca de que es además análoga, de una parte, a la dialéctica y, de otra parte, a los razonamientos sofísticos» $\left(4.11359^{\mathrm{b}} 8-13\right)$.

2.1 Acreditado el estatuto técnico de la retórica, pasemos a considerar sus señas de identidad como disciplina. Para empezar destacan sus objetivos específicos: uno más bien teórico, el otro más bien práctico. El primero ya es conocido por la declaración del propósito de la retórica aristotélica: no consiste precisamente en persuadir, sino en estudiar los medios de persuasión disponibles a través del discurso en cada caso particular. Así cumple además un requisito de su condición de arte: el examen y la explicación de los éxitos de su ejercicio, deliberado o espontáneo (I 1.1, 1354a10-12). Por otro lado, al atenerse a los medios de persuasión antes que a sus resultados efectivos en la práctica, esta retórica presta especial atención a los aspectos y criterios de eficiencia discursiva y racional interna, al margen de la eficacia externa que persiguen los manuales de los "rhetores tecnógrafos". Pero esa eficiencia también guarda relación con la formación de un juicio sobre la cuestión debatida, punto que nos remite al segundo objetivo, el de orden práctico. Consiste en formar un juicio y elegir una opción, por ejemplo un curso de acción, en razón de las pruebas suasorias aducidas.

Las pruebas propias del arte siguen siendo hoy las señas más afamadas de la retórica de Aristóteles. Conviene presentarlas de acuerdo con su motivación originaria: «Puesto que la retórica tiene por objeto formar un juicio $<\ldots>$, es preciso atender no solo a cómo sea demostrativo o digno de crédito el discurso, sino también a cómo ha de presentarse uno mismo [i.e. el hablante o locutor] y a cómo ganarse al que juzga [el alocutario o auditorio]» (II.1

${ }^{7}$ El término ha sido acuñado por Pablo Ródenas para un ideario integrador de motivos políticos y éticos, en el sentido actual de ética -una ética alejada del saber acerca de los "caracteres" aristotélico-. 
1377b20-24) ${ }^{8}$. Así pues, son estas líneas las que van a marcar las pruebas propias del arte, es decir las que el agente discursivo puede montar mediante su discurso, a diferencia de las pruebas impropias o ajenas con las que puede contar antes o al margen del discurso, como los datos o los testimonios. «Entre las pruebas retóricas, las que pueden obtenerse mediante el discurso son de tres especies: unas residen en el talante [êthos] del que habla, otras en poner en cierta disposición [páthos] al oyente y las últimas en el discurso [lógos] mismo por lo que este demuestra o parece demostrar. Pues bien, $<$ se prueba $>$ por el talante cuando el discurso es dicho de tal forma que hace al orador digno de crédito. $<\ldots>$ Por otro lado, $<$ se prueba mediante la disposición $>$ de los oyentes, cuando estos son inducidos a un estado de ánimo a través del discurso. $<\ldots>$ En fin, los hombres se persuaden por el discurso cuando les mostramos la verdad o lo que parece serlo a partir de lo convincente en cada caso particular» (1.2 $\left.1356^{\mathrm{a}} 1-19\right)$.

Hay dos puntos notables en este planteamiento: 1/ Los tres tipos de pruebas obran a través del discurso, así que hemos de distinguir entre este logos o discurso básico, el lenguaje de la comunicación y el entendimiento, y el logos argumentativo, el discurso específicamente retórico de las pruebas suasorias o "demostrativas". 2/ Los tres operan conjuntamente, no disyuntivamente, de modo que los procesos de inducción retórica no son monológicos, sino interactivos, y además envuelven a los agentes discursivos en su conjunto, no una facultad en particular (e.g. la racional o la emotiva). El punto 1/ previene contra la búsqueda de una suerte de protológica del discurso racional en el lenguaje comunicativo mismo; el punto 2/ contra las oposiciones al uso que separan el claro rigor del logos de la oscura trama del ethos y pathos en la retórica.

Aristóteles ofrece algunos detalles sobre cada uno de los tipos. Las pruebas argumentativas o correspondientes al logos son el entimema, de estructura deductiva, y el ejemplo, más bien inductivo. Aristóteles sigue siendo fiel a sí mismo y precisa que si bien el ejemplo no es menos convincente, los discursos basados en entimemas están mejor considerados (1356 24$)$. El entimema, en particular, es «el cuerpo de la persuasión» $\left(1354^{\mathrm{a}} 15\right)$ y se dirige no solo al entendimiento ${ }^{9}$, sino al hombre completo, dado el carácter integrado u holista tanto de la motivación del discurso retórico como de su eficiencia práctica en orden a la formación del juicio. El entimema representa, por lo demás, una de

\footnotetext{
${ }^{8}$ No está de más reparar en la concepción holista o integrada de la formación del juicio que supone esta declaración aristotélica, frente a su tratamiento tradicional como instrucción lógicoepistémica, sin más, o como formación primordialmente racional (cf., por ejemplo, la Lógica o Arte de pensar de Port Royal).

${ }^{9}$ «El intelecto solo <...> no mueve nada» (Ética Nicomáquea 1139b35-36).
} 
las muestras más elocuentes de la cooperación entre los distintos tipos de pruebas, pues su efectividad suasoria descansa en la comprensión y la complicidad -en la conveniente disposición pathética- del interlocutor o del oyente ${ }^{10}$.

A su vez, «el talante constituye por así decirlo el más firme medio de persuasión» (1356 13 ), pero a condición de que obre a través del discurso. Así pues, la retórica aristotélica no reconoce como pruebas propias en este sentido de êthos el prestigio personal o la autoridad institucional que asisten previamente al agente discursivo, frente a lo que será norma en la tradición desde la retórica romana hasta nuestros días. Según Aristóteles, se persuade «por el êthos cuando el discurso es dicho de tal forma que hace al orador digno de crédito» (1356 5-6). Hay tres causas o motivos concurrentes de que un agente discursivo sea fiable o digno de crédito: (i) la prudencia o inteligencia práctica (phrónesis), (ii) la virtud (areté) y (iii) la buena disposición o franqueza (eúnoia). La mera manifestación de inteligencia práctica, no acompañada de signos de virtud ni de buena disposición, induciría a dudar sobre las intenciones del orador; mientras que las señales de prudencia y de virtud, sin muestras de franqueza, inducirían a dudar sobre su grado de implicación o compromiso con lo que propone.

$\mathrm{Y}$, en fin, el poder de convicción del entimema y el reconocimiento del talante fiable del emisor requieren a su vez la disposición receptiva, el oportuno estado de ánimo y la complicidad del receptor. Cabe decir, en general, que el orador persuade a los oyentes «cuando estos son movidos a un estado de ánimo por medio del discurso», $1356^{\mathrm{a}} 13-14$. Ahora bien, el páthos aristotélico no deja de tener una dimensión cognitiva pues supone considerar el estado del sujeto, el objeto de la emoción producida y el motivo de esta inducción (en el libro II de la Retórica 1.3, 1378 23-24, puede verse un examen de la ira según estos tres parámetros). De ahí que sea preferible entenderlo no como pasión, en la medida en que las pasiones incluyen pulsiones no cognitivas, sino en el sentido de emoción o estado o disposición de ánimo inducidas a través del discurso.

Un último rasgo distintivo de la retórica es el constituido, como ya hemos tenido ocasión de ver, por su dominio de referencia: el discurso público. Dentro de este ámbito, Aristóteles considera que es preciso que haya tres géneros de discurso retórico en atención a las que juzga tres clases posibles de auditorio: el género deliberativo (symbouleutikón), el judicial (dikanikón), y el epídíctico. Valga su caracterización según el siguiente esquema compuesto con arreglo a los propios parámetros aristotélicos:

${ }^{10}$ Sobre la recuperación actual de este y otros aspectos olvidados por la tradición empeñada en tratar el entimema como un razonamiento defectivo o un silogismo deficiente, vid. Vega Reñón (2004). 
Vindicación y elogio de la retórica deliberativa: glosas de Aristóteles

Objeto propio Propósito: determinar Refer. temporal

\begin{tabular}{lccc}
\hline Deliberativo: & $\begin{array}{c}\text { Recomendación / } \\
\text { disuasión }\end{array}$ & $\begin{array}{c}\text { Lo conveniente / } \\
\text { perjudicial }\end{array}$ & Al futuro \\
\hline Judicial: & $\begin{array}{c}\text { Acusación / } \\
\text { defensa }\end{array}$ & $\begin{array}{c}\text { Lo justo / } \\
\text { injusto }\end{array}$ & Al pasado \\
\hline Epidíctico: & $\begin{array}{c}\text { Elogio / } \\
\text { censura }\end{array}$ & $\begin{array}{c}\text { Lo honroso / } \\
\text { vergonzoso }\end{array}$ & $\begin{array}{c}\text { Presente o } \\
\text { actualizada }\end{array}$ \\
\hline
\end{tabular}

Por lo demás, al propósito distintivo de cada género cabe añadir la consideración eventual de los característicos de otros géneros como propósitos adicionales o complementarios (I 3.1-2, 1358 $37-1359^{\mathrm{a}} 6$ ). Esta "teoría de los géneros retóricos" es, quizás, uno de los temas menos sustanciales y más discutibles de la retórica aristotélica, sin ser, por lo demás, una clasificación exclusiva de Aristóteles.

Como a partir de ahora el género que nos va a interesar es el deliberativo, no estará de más adelantar que el discurso deliberativo cuenta con ciertos valores propios. Aristóteles destaca, por ejemplo, una capacidad de autorregulación que lo distingue del judicial: «en los discursos ante el pueblo aprovecha menos hablar de lo que es ajeno al asunto» (1354 $28-29)$, frente al posible éxito de las digresiones y maniobras de distracción que suelen emplear los litigantes. Con esta capacidad de autorregulación colectiva se relaciona otro valor, el de ser menos engañoso: «la oratoria deliberativa es menos engañosa que la judicial por ser más propia de la comunidad» (1354 $30-31)$.

\section{Aristóteles sobre la deliberación y el discurso público}

En Aristóteles nos encontramos con dos planteamientos principales de la deliberación, uno más bien reflexivo y privado representado por el uso de boúleusis en la Ética Nicomáquea, el otro referido al discurso público en la Retórica en los términos ya conocidos de "género deliberativo [genos symbouleutikón]". El primero tiene que ver ante todo con la prudencia: «parece propio del hombre prudente el ser capaz de deliberar rectamente sobre lo que es bueno y conveniente para sí mismo en orden al vivir bien en general» (EN 1140a25-30). Según esto, la deliberación viene a ser una ejercitación de la prudencia «como modo de ser racional, verdadero y práctico respecto de lo que es bueno y malo para el hombre» $\left(1140^{\mathrm{b}} 4-5\right)$. Desde un punto de vista discursivo, consiste en un razonamiento práctico que no se ocupa de los fines u objetivos que uno se ha propuesto, sino de los medios pertinentes para alcanzarlos o cumplirlos 
(1112 $\left.{ }^{\mathrm{b}} 11-12\right)$. Así pues, supone una consideración reflexiva y ponderativa de las condiciones que rodean la decisión de emprender una acción con miras a conseguir dichos propósitos. Por otro lado, el planteamiento retórico de la deliberación ya había sido avanzado por la Retórica a Alejandro atribuida a Anaxímenes, texto anterior a la versión final de la Retórica aristotélica y relativamente independiente. Esta Retórica habla de la deliberación como un género de discurso público o político [genos demegorikón] que tiene lugar en el marco de una discusión asamblearia sobre una resolución y puede proceder tanto a efectos suasorios como disuasorios al respecto ${ }^{11}$. Ahora bien, ninguna de las dos Retóricas, la de Aristóteles y la atribuida a Anaxímenes, marca diferencias entre los usos privados o conversacionales y los usos públicos o políticos del discurso deliberativo y, menos aún, los considera incompatibles. Baste una muestra aristotélica: «Lo propio de la deliberación [symboúleusis] es la persuasión y la disuasión pues una de estas dos cosas es lo que hacen siempre tanto los que aconsejan en privado, como los que hablan en público acerca de un asunto común» (Retórica, 1358 7 7-9). De manera que, para empezar, podemos servirnos de la Ética Nicomáquea $(E N)$ y de la Retórica $(R)$ como fuentes para caracterizar la deliberación, en general, y la deliberación pública o política en particular.

3.1 La concepción aristotélica de la deliberación, en general, se puede concretar de modo sumario con respecto a su objeto, su marco discursivo y sus relaciones con la elección correspondiente. Para empezar, deliberamos sobre lo que depende de nosotros y nos concierne. Así pues, no deliberamos sobre lo necesario, lo inmutable o lo eterno, porque todo esto sobrepasa nuestra capacidad de actuación. Tampoco deliberamos sobre el puro azar porque también está fuera de nuestro control y ocurre al margen de nuestras posibilidades de intervención. Y, en fin, una comunidad de ciudadanos tampoco delibera sobre lo que no le concierne como, por ejemplo, una constitución política ajena. «Ante todo se ha de establecer sobré qué bienes o males delibera el que hace un discurso deliberativo, puesto que no cabe deliberar sobre cualquier cosa,

11 Pero su visión es más comprensiva que la aristotélica: «En general, la persuasión consiste en el apoyo a ciertas intenciones, discursos o acciones; la disuasión consiste en su desaprobación. De acuerdo con esta definición, el que persuade tiene que demostrar que las cosas que él exhorta a hacer son justas, legales, convenientes, nobles, gratas y fáciles de ejecutar; y si no, cuando exhorte a hacer cosas difíciles, ha de demostrar que son posibles y que es necesario hacerlas. El que disuade de algo debe oponerse a ello por medio de lo contrario $<\ldots>$. Todo hecho se presta a ambos puntos de vista, así que a nadie que sostenga uno cualquiera de los dos planteamientos, le faltará qué decir» (Retórica a Alejandro, 1, 1421 b3-5).Vid. la edición de J. Sánchez Sanz. Salamanca: Ediciones Universidad de Salamanca, 1989. 
sino solamente sobre lo puede ocurrir o no, habida cuenta de que no es posible ninguna deliberación sobre lo que necesariamente es o será, o sobre lo que es imposible que exista o llegue a suceder ${ }^{12}$. Más aún, no cabe deliberar acerca de todas las cosas posibles. Puesto que, entre los bienes que pueden acaecer o no, hay algunos que suceden o por naturaleza o por azar, respecto de los cuales para nada sirve la deliberación. Es evidente, en cambio, sobre qué cosas es posible deliberar. Son aquellas que dependen de nosotros y cuya producción está en nuestras manos» ( $R, 1359^{\mathrm{a}} 30-39$; cf. $E N$ III $\left.3,1112^{\mathrm{a}} 18-1113^{\mathrm{a}} 14\right)$.

Por lo que se refiere al marco discursivo de la deliberación cabe hacer un resumen parecido. La deliberación se mueve en el mundo de las opiniones plausibles, es decir endoxásticas o más o menos acreditadas socialmente ${ }^{13} \mathrm{y}$, en esta línea, suele remitirse a ciertas máximas o lugares comunes de dominio público. Sus proposiciones hacen referencia a lo que ocurre por lo regular o con frecuencia, a casos o situaciones cuyo desenlace es incierto o comporta cierta indeterminación. Según esto, ¿podríamos pensar en una suerte de entimemas rebatibles o razonamientos derrotables avant la lettre? Sus propuestas versan sobre lo actuable (praktá), factible o realizable por los miembros de la comunidad involucrada en el discurso, y se ocupan de modo característico de los medios conducentes al fin o al objetivo práctico propuesto. Este es un punto que suele considerarse tan peculiar de Aristóteles como discutible: se delibera sobre los medios, no sobre los fines. Puede ahorrarnos algunas discusiones caer en la cuenta de lo que Aristóteles entiende por tales fines. Unos son los propósitos o los objetivos pretendidos por la deliberación en cuestión, así que una vez que sabemos que están a nuestro alcance, no tendría más sentido deliberar acerca de ellos que deliberar sobre la propia deliberación. Otros, expresamente mencionados, son los fines inherentes a la naturaleza o al oficio de los agentes deliberativos: Aristóteles tampoco juzgaría muy razonable que deliberaran acerca de sí mismos, por ejemplo acerca de si el médico debe proponerse curar o el piloto conducir su barco a buen puerto o el hombre ser feliz.

Por desgracia, la deliberación sobre los medios oportunos no asegura la consecución del fin propuesto. Pero parece garantizar al menos una resolución o una decisión consecuente con el curso de la deliberación. Aristóteles declara una tesis fuerte a este respecto: «se elige lo que se ha decidido después de la deliberación» (EN III $31113^{\mathrm{a}} 5$ ), «cuando decidimos después de deliberar, deseamos de acuerdo

12 Está claro que para Aristóteles las necesidades que cuentan son las lógicas o las naturales; no parecen existir las que nosotros podríamos calificar de "necesidades sociales".

${ }^{13}$ Recordemos que las opiniones de este tipo son aquellas que «parecen bien a todos o a la mayoría o a los sabios y, entre estos, a todos, a la mayoría o a los más conocidos y reputados» (Tópicos, 100²1-23). 
con la deliberación» (EN III 3, 1113 12 -13). Esta tesis suscita dos interrogantes. Uno podría resultarle natural al propio Aristóteles en la medida en que estaba familiarizado con la cuestión de la debilidad de la voluntad (akrasia) planteada a propósito de un agente incontinente, incapaz de proceder de acuerdo con lo que considera la mejor opción ${ }^{14}$. Cabe preguntarse entonces si, habiendo elegido una opción de acuerdo con la deliberación, nos vemos abocados luego a actuar en consonancia con esa decisión. No está clara la posición de Aristóteles acerca de la cuestión en general. Pero, en el presente contexto en particular, si nos atenemos al caso de una buena deliberación, podríamos inclinarnos por una respuesta afirmativa. Pues la buena deliberación es no solo la que discurre rectamente de acuerdo con las reglas de la prudencia, sino la que se propone un bien y es eficiente a este respecto, tanto con respecto al tiempo como con respecto al modo de conseguirlo (vid. ENVI 9, 1142 17 -35). El otro problema que la tesis puede plantear es, en cambio, muy ajeno a Aristóteles y proviene del estudio actual de las tomas de decisión colectivas como las que se esperan de las deliberaciones públicas. Se trata del llamado "dilema discursivo" o disyuntiva generada por un proceso deliberativo que se presta a dos resoluciones distintas según se atienda al juicio mayoritario sobre las premisas del razonamiento práctico pertinente o al juicio mayoritario sobre su conclusión ${ }^{15}$. Según esto, la deliberación colectiva, bajo ciertas condiciones normales, puede conducir a una resolución equívoca, a una disyuntiva, aunque el proceder discursivo de cada uno de los individuos involucrados sea conducente a una conclusión coherente y unívoca. Así que también representa un problema para el tratamiento indiferenciado de la deliberación individual privada y la deliberación pública colectiva.

3.2 Como habíamos visto al recordar los antecedentes de la contribución de Aristóteles a la retórica deliberativa, los cargos que esta debía afrontar solían ser de dos tipos, a veces solidarios entre sí como en algunos diálogos de Platón. (a) Unos eran más bien teóricos o de carácter epistemológico: se cifraban en la incapacidad o en la indiferencia de la retórica con respecto a los valores del discurso (por ejemplo rigor, verdad, fiabilidad) o al conocimiento (por ejemplo, legimitidad epistémica). (b) Otros resultaban en cambio más bien prácticos: denunciaban la inviabilidad de un discurso público razonable debida a los intereses encontrados de los individuos de la multitud y a su vulnerabilidad frente a las tretas y engaños de los expertos en las (malas) artes del discurso. Veamos brevemente la vindicación aristotélica en ambos casos.

14 Un caso paradigmático es el que Ovidio hace confesar a su Medea: «Veo lo mejor y lo apruebo, pero hago lo peor (Video meliora proboque / deteriora sequor)» (Metamorfosis, 7.20-21).

15 Vid. por ejemplo Christian List (2009), "The discursive dilemma and public reason". 
(a) Frente a los cargos de carácter más bien teórico o epistemológico

Bueno será partir de una advertencia general que descalifica de entrada las demandas de rigor no pertinentes en el discurso retórico: «Es propio de la persona instruida buscar en cada caso la exactitud que le conviene por su naturaleza: tan absurdo sería aceptar que un matemático se sirviera de la persuasión como exigir a un retórico demostraciones» (EN I 3, 1094²3-27). Según esto, queda fuera de lugar la confrontación platónica de la retórica con la geometría, para dejar en evidencia la falta de rigor de la primera.

A partir de ahí un paso adelante es vindicar los medios discursivos y cognitivos propios de la argumentación retórica; en particular, la vindicación de los argumentos que discurren por referencia a lo probable (eikós) o a lo que ocurre la mayoría de las veces (hos epi tò poly), y en términos de lo plausible (éndoxon) o lo verosímil (hómoion tô alethê̂). «Corresponde a una misma facultad reconocer tanto lo verdadero como lo verosímil, y los hombres tienden por naturaleza de modo suficiente a la verdad y la mayor parte de las veces la alcanzan. Así que estar en disposición de discernir acerca de lo plausible es propio de quien está en la misma disposición respecto de la verdad» ( $R$ I $\left.1.41355^{\mathrm{a}} 15-19\right)$. Esto supone, de una parte, que el ser humano tiene la facultad de conocer de modo que es un conocedor potencial de la verdad y las potencialidades naturales tienden a realizarse. De otra parte, implica que esta disposición natural del ser humano no solo funda ónticamente, sino además legitima epistémicamente sus pretensiones cognitivas tanto en el campo de la verdad demostrada como el terreno de las proposiciones plausibles.

Por otro lado, la retórica puede y debe rendir ciertos servicios derivados en orden a la formación y el establecimiento del juicio: tienen que ver con la expresión adecuada y eficiente de las proposiciones y propuestas en pugna, y cabría reprochar a la retórica que no los cumpliera. Según Aristóteles, «la verdad y la justicia son por naturaleza más fuertes que sus contrarios, de modo que si los juicios no se establecen como es debido, será forzoso que sean vencidos por tales contrarios, lo cual es por cierto digno de reprensión» $\left(R\right.$ I $1.51355^{\mathrm{a} 22}$-23). En otras palabras, sostiene Aristóteles que «siempre, en términos absolutos, lo verdadero y lo mejor son por naturaleza más probatorios y más persuasivos» (ibd. 1355 37-38). En consecuencia, no solo hemos de reconocer y confiar en el poder natural de un discurso para expresar cabalmente lo verdadero y lo justo, sino que somos responsables de cuidar de su eficiencia, pues un uso indebido resultaría culpable de que ese poder se viera desvirtuado o inhibido. 
(b) Frente a los cargos de carácter más bien práctico

Para empezar, reparemos en que a esa confianza en la disposición natural de nuestras facultades discursivas y cognitivas a su ejercicio racional en ciencias como las matemáticas y a su ejercicio razonable en artes como la retórica, se añade la capacidad de discriminación entre usos legítimos o genuinos y usos sofísticos o aparentes que la retórica comparte con la dialéctica. Entonces cabe oponer al cargo de la irracionalidad y credulidad del auditorio que se cierne sobre el discurso público, la confianza en nuestra tendencia natural hacia lo verdadero y lo justo, así como nuestra responsabilidad en la discriminación entre usos discursivos apropiados e inapropiados.

Pero al igual que en el caso anterior, la vindicación de Aristóteles no consiste solo en rebatir las acusaciones de su entorno; también se preocupa por mostrar las virtudes y los servicios positivos que cabe esperar de la deliberación pública.

Un punto interesante a este respecto es su referencia ya citada a una especie de autorregulación del discurso deliberativo. En principio, cabría suponer que las razones públicas deberían ser imparciales e impersonales, o consistir en alegaciones válidas o aceptables para todos los involucrados -han sido supuestos habituales incluso en nuestros días-. Ahora bien, el discurso retórico trae consigo la consideración de los talantes o "caracteres" y de las emociones o disposiciones, de modo que las razones en este medio no resultan impersonales o imparciales; han de ajustarse además al caso particular planteado. Amén de esta eficiencia concreta del discurso retórico en general, el discurso deliberativo cuenta con un mecanismo específico de regulación: consiste en el propósito o interés común que guía la interacción discursiva. Recordemos que «la oratoria deliberativa es menos engañosa que la judicial por ser más propia de la comunidad» $(R, 1354 \mathrm{~b} 30-31)$. Según esto, el desinterés o la imparcialidad serían precisamente motivos de no compromiso y de escasa fiabilidad. Es decir: tendrían consecuencias negativas frente a los supuestos habituales, antes señalados, acerca del recto uso de la razón en las cuestiones de interés y de dominio público ${ }^{16}$.

Otra referencia de importancia es la que opone las virtudes y servicios de la buena deliberación a su presunta perversión o, cuando menos, inutilidad. De modo que «si deliberar rectamente es propio de los prudentes, la buena deli-

${ }^{16}$ Vid. Bernard Yack (2006), "Rhetoric and public reasoning”. No es extraño que algunas observaciones críticas de defensores actuales de la deliberación democrática contra ciertas propuestas pretendidamente "racionales" como las de Rawls o Habermas, se inspiren expresamente en este Aristóteles. 
beración será una rectitud con arreglo a lo conveniente, con relación a un $<$ buen $>$ fin, y donde la prudencia descansa en un juicio verdadero» (EN VI.9, 1142 $333-35)$. Es decir, en la buena deliberación concurren criterios de calidad interna, como la fundamentación prudente en un juicio verdadero y la aspiración a un bien, y criterios de eficiencia práctica, como el modo de proceder en orden a su objetivo y el tiempo de la resolución. Aristóteles también parece sugerir que se incluyen el acierto y el éxito de la resolución, al referirse a la «rectitud que alcanza un bien»; puede que entonces la estimación de la buena deliberación sea por lo regular más retrospectiva que prospectiva.

3.3 Aristóteles no se contenta con la vindicación de la deliberación pública. Además procura rehabilitar su papel en la vida política de la ciudad al asociar, en la línea del Discurso de Pericles, el ejercicio de ambas, ciudadanía y deliberación, y apostar por la competencia del colectivo. Hay declaraciones elocuentes en este sentido: «Cada individuo será peor juez que los expertos, pero todos juntos serán mejores o al menos no peores» (Política III 11, 1282a 16-17). Por otra parte, aunque no esté al alcance de todos hacer o promulgar las normas constitucionales que rigen la vida de la comunidad, el ciudadano o usuario común puede estar tanto o más capacitado para juzgarlas que el experto: "Así como en algunas cosas no es el que las hace el mejor juez o el único, sino que puede juzgar mejor el que las usa» (ibd. 1282 $18-24)$.

En todo caso, más allá de las constituciones escritas y las cuestiones jurídicas técnicas que demandan «personas de buen sentido y capaces de legislar y hacer justicia» (ibd. $\left.1354^{\mathrm{b}} 1-2\right)$, la deliberación pública recobra su protagonismo: «En cuanto a las cuestiones que la ley no puede decidir en absoluto o no puede decidir bien ${ }^{17}$, ¿deben estar al arbitrio del mejor o al de todos? En la actualidad todos reunidos juzgan, deliberan y deciden, y estas decisiones se refieren todas a casos concretos. Sin duda cada uno de ellos, tomado individualmente, es inferior al mejor, pero la ciudad se compone de muchos y por la misma razón que un banquete al que muchos contribuyen es mejor que el dado por uno solo, también juzga mejor una multitud que cualquier individuo. Además, un gran número $<$ de ciudadanos $>$ es más difícil de corromper, por ejemplo una gran cantidad de agua se corrompe más difícilmente que una pequeña, y así una muchedumbre es más incorruptible que unos pocos $<\ldots>$. Suponga-

${ }^{17}$ Fuera del dominio de las leyes escritas están, sin ir más lejos, las circunstancias de su aplicación. Y fuera del dominio de las leyes en general quedan las decisiones que suponen juicios "apasionados", es decir no exentos de emociones y disposiciones anímicas: el alma, apasionada por naturaleza, delibera mejor sobre las cosas concretas (Política III.15, 1286a19-21). 
mos que hay cierto número de hombres y ciudadanos buenos: ¿será más incorruptible el gobernante individual o el número mayor de hombres todos buenos? Evidentemente el número mayor. Podrá replicarse que en el número mayor surgirán disensiones, cosa que no puede ocurrir si se trata de uno solo. Pero a esto cabe responder que son de alma recta, como aquél <que era el $>$ único» (Política, III 15, 1285 24- ${ }^{\mathrm{b}} 3$; cf. 11, 1281 $43^{\mathrm{a}}{ }^{\mathrm{b}}$ ). De ahí concluye Aristóteles que la aristocracia, o gobierno de unos cuantos buenos, es mejor para las ciudades que la monarquía, o gobierno de uno solo. Ahora bien, el razonamiento resultaría extensible al caso de la democracia si la mayoría de los ciudadanos fuera buena gente. Algo así parece sugerir el llamado "teorema del jurado" de Condorcet. Un grupo ha de tomar una decisión entre dos opciones, una correcta y la otra incorrecta. Si la probabilidad independiente de que cada miembro tome la decisión correcta es mayor que 0.5 , entonces la probabilidad de que la mayoría del grupo acierte, aumenta a medida que crece el número de individuos que componen el grupo. Por otro lado, no faltan experimentos en psicología social donde los grupos a partir de 3 miembros han obtenido mejores resultados que el mejor de sus individuos ${ }^{18}$. Con todo, el desarrollo actual de la investigación experimental en este ámbito parece mostrar que el rendimiento del grupo depende ciertas condiciones iniciales y del tipo de asuntos considerados, por ejemplo de si hay o no posturas previamente establecidas, de la diversidad cognitiva que enriquece a un grupo heterogéneo frente a sus individuos o, en fin, de si se supone que el punto en cuestión tiene una solución efectiva ${ }^{19}$.

3.4 No todo el mundo es buena gente, pero se supone que la deliberación pública puede mejorar al ser humano, al menos en su calidad de ciudadano o miembro de una comunidad política. El valor de la publicidad puede apreciarse a través de una emoción educativa como la vergüenza ${ }^{20}$. A juicio de Aristóteles, la deliberación pública es una deliberación cara a cara sobre cuestiones de interés común para los miembros de la comunidad, y en este carácter presencial reside la clave de su publicidad. Según un proverbio que

${ }^{18}$ Han sido pruebas de correlación entre letras y números, vid. P.R. Laughlin, E.C. Hatch, J.S. Silver \& L. Boh (2006), "Groups perform better than the best individuals on letters-tonumbers problems: Effects of group size”, Journal of Personality and Social Psychology, 90/4: 644-651.

${ }^{19}$ Cf., por ejemplo, Carl Sunstein (2006), "The surprising failures of deliberating groups" en Infotopia: How many minds produce knowledge, pp. 45-73; Helene R. Landemore (2012), "Why the many are smarter than the few and why it matters".

${ }^{20}$ Es una disposición singularmente valiosa para el que ha de aprender pautas de comportamiento social (EN IV.9 1128b10-18). 
sanciona con su aprobación, «la vergüenza está en los ojos [de los demás]» $(R$, $\left.1384^{\mathrm{a}} 34\right)^{21}$. Es una sentencia que, en principio, cabe entender en la línea en que John Stuart Mill trata la publicidad presencial de «estar bajo los ojos de otros» ${ }^{22}$. Según Mill, el valor de esta publicidad es incalculable en razón de su doble poder: inhibitorio, al impedirnos sostener lo que no tiene ninguna posibilidad de ser defendido de modo plausible; y motivador, al movernos a la reflexión y la ponderación previas a una acción o una declaración si estamos expuestos a rendir cuentas de ellas ante los que nos rodean. Pero en Aristóteles tiene todavía mayor importancia, pues la vergüenza guarda una estrecha relación con la reputación -consiste en «imaginarse la pérdida de reputación» $\left(R, 1384^{2} 24\right)-$, y por ende con la retórica. Más aún, no solo tiene una repercusión directa en el êthos del agente discursivo, sino que contribuye a la formación del propio carácter mediante la interiorización de la obligación de rendir cuentas para preservar justamente la pretendida reputación. El poder educativo de la publicidad presencial da la medida del valor de la retórica deliberativa conforme a estos tres puntos: (i) La capacidad para la deliberación pública supone el lógos como facultad natural, propia del animal social por excelencia, pero se desenvuelve como una competencia adquirida con su ejercicio interactivo. (ii) Su adquisición comporta el desarrollo de disposiciones determinantes por un lado de la formación del propio juicio resolutivo en el curso de la deliberación y, por otro, del carácter o talante y la reputación del agente discursivo. (iii) La publicidad presencial obra justamente como un medio motivador y normativo en ambos respectos hasta el punto de que, en palabras de Pierre Aubenque, «la deliberación consigo mismo no es sino la forma interiorizada de la deliberación en común" (1999: 128).

\section{Revisión a la luz de nuestros conocimientos y problemas}

Nuestro interés actual por la Retórica de Aristóteles no debe ocultarnos las distancias y diferencias que nos separan. Así que, para terminar, mencionaré un par de limitaciones y de aspectos críticos del planteamiento aristotélico que hoy saltan a la vista, sin mayor pretensión que la de invitar a una consideración más detenida.

${ }^{21}$ En otro lugar, apela a «los ojos de los magistrados» para preservar el pudor y el respeto de los hombres libres en el gimnasio (Política, 1331ª40-41).

22 Considerations on Representative Government (1876: 84), citado en Paul Neuwenburg (2004): 450 . 
4.1 Por lo que se refiere a las limitaciones, creo que al menos pueden apreciarse de dos tipos o en dos planos de ocurrencia. Unas tienen que ver con el propio discurso deliberativo, otras corresponden más bien a la estructura interactiva de la deliberación pública. Entre las primeras, llaman la atención dos en particular:

(1) Aristóteles parece limitarse a tratar con proposiciones sin llegar a considerar propuestas ${ }^{23}$, pese a su lúcido reconocimiento del silogismo práctico bajo la forma canónica medios-fines. Pero este esquema argumentativo instrumental, medios-fines, tampoco es el único paradigma de razonamiento práctico de que hoy disponemos. Por ejemplo, otro patrón familiar concluye en una propuesta sobre un curso de acción viable, recomendable o preferible, proceder especialmente indicado en el género de discurso que el propio Aristóteles distingue como deliberativo.

(2) Aristóteles tampoco parece considerar expresamente la ponderación de las diversas alegaciones, razones o argumentos, o incluso líneas de argumentación sobre la base de principios o de valores distintos, que pueden concurrir en el proceso de una deliberación. En este sentido, también es llamativa la exclusión indiscriminada de los fines -cualquier tipo de fines- del terreno de la deliberación; se diría complementaria del papel paradigmático concedido a su esquema instrumental de silogismo práctico.

Las limitaciones que se acusan en el otro plano señalado, dentro de la estructura interactiva de la deliberación, también son notorias, pero aquí es donde resultan determinantes los estudios y las discusiones recientes acerca de la deliberación pública y a propósito de la democracia deliberativa. Naturalmente, no cabe reprochar a Aristóteles no haberlas previsto. Bastante ha hecho si ha dado lugar a que algunas reivindicaciones de nuevas alternativas declaren inspirarse en ciertos puntos de su retórica deliberativa o se hagan eco de la famosa tríada: lógos, êthos, páthos. En todo caso, Aristóteles no considera las

${ }^{23}$ Las propuestas son, sin ir más lejos, actos de habla directivo-comisivos de la forma: 'lo indicado [oportuno, pertinente, conveniente, debido, obligado...] en el presente caso es hacer [no hacer] A' con una dirección de ajuste del mundo al lenguaje, frente al carácter constatativo o asertivo de las proposiciones habituales, con una dirección de ajuste del lenguaje al mundo. En este caso, si una proposición fuera verdadera, la contraria sería falsa; mientras que en el primer caso, si una propuesta fuera razonable, la contraria también podría serlo. Las propuestas pueden considerarse conclusiones de argumentaciones prácticas revisables o rebatibles que, por lo demás, también envuelven proposiciones, amén de poder incluir actos de habla de otros tipos. En todo caso demandan una lógica deóntica un tanto peculiar. 
condiciones ideales que, desde los años 1980 y 90, suelen arbitrarse para establecer la calidad democrática de una interacción deliberativa, como las demandas de $(i)$ inclusión de todos los afectados por el asunto y las opciones en juego; (ii) publicidad y transparencia por parte del emisor de la información pertinente; (iii) autonomía por parte del receptor, así como respeto de su inteligencia y capacidad de decisión; (iv) simetría y reciprocidad de la relación entre los involucrados en la deliberación, de modo que todos tienen el mismo derecho a hablar y a ser escuchados, y el mismo derecho a proponer y a pedir cuenta y razón de las propuestas ajenas. Sin embargo, sus ideas de la visibilidad presencial, cara a cara, no dejar de ser sugerentes para nuestra concepción de deliberación democrática.

4.2 Este último punto puede justamente anunciar uno de nuestros nudos de problemas en el contexto de los programas de la democracia deliberativa, el de las relaciones entre la perspectiva micro de la deliberación democrática, la deliberación presencial en foros y grupos acotados, y la perspectiva macro de la democracia deliberativa, la abierta a los dominios políticos o socio-institucionales generales del discurso público. Actualmente el interés y la investigación dentro de la primera son prometedores y van en ascenso, mientras que la segunda parece en declive debido a la conciencia de sus dificultades de concreción y a cierto escepticismo. Hay quien como Chambers (2009) se pregunta si la democracia deliberativa no ha abandonado el ideal de una democracia de masas. En cualquier caso, tenemos pendiente en nuestros días la búsqueda de estrategias para, de una parte, preservar la coherencia entre las concepciones programáticas de la deliberación y la democracia ${ }^{24} \mathrm{y}$, de otra parte, salvar las distancias entre la práctica de la deliberación en grupos controlables y las demandas de una sociedad democrática.

Pero no es este el único foco de problemas relacionados con la visibilidad de la retórica deliberativa aristotélica. Si recordamos el papel educativo y normativo de la vergüenza, del estar bajo la mirada de los otros, en la deliberación presencial, ¿qué podemos pensar del discurso electrónico y de la deliberación mediante interfaces de dispositivos en red, una comunicación que ha sustituido voces y miradas por direcciones IP, una comunicación "desvergonzada"? ¿Cómo funciona la retórica deliberativa en este nuevo marco? El problema se agudiza si tenemos en cuenta que precisamente ese discurso electrónico viene a ser nuestro medio de deliberación de y entre democracias.

${ }^{24}$ Cf. por ejemplo la discusión de C. Lafont (2006), "Is the ideal of a deliberative democracy coherent?". 


\section{BIBLIOGRAFÍA}

Abizadeh, A. 2002, "The passions of the wise: Phronesis, rhetoric, and Aristotle's passionate practical deliberation", The Review of Metaphysics, 56/2: 267-297.

Abizadeh, A. 2007, "On the philosophy/rhetoric binaries", Philosophy and Social Criticism, 33/4: 445-472.

Aubenque, P. 1999, La prudencia en Aristóteles. Barcelona: Crítica.

Benhabib, S. 1996, "Toward a deliberative model of democratic legitimacy", en S. Benhabib, ed., Democracy and difference: Contesting the boundaries of the political. Princeton, NJ: Princeton University Press; pp. 67-94.

Brunschwig, J. 1996, "Aristotle's rhetoric as a 'counterpart' to dialectic", en A. Rorty, ed., Essays on Aristotle's Rhetoric. Berkeley, CA: University of California Press, pp. 34-55.

Chambers, S. 2009, "Rhetoric and the public sphere: Has deliberative democracy abandoned mass democracy?", Political Theory, 34/4: 427-438.

Cohen, J. 1997, “Deliberation and democratic legitimacy”, en J. Bohman y W. Rehg, eds., Deliberative democracy: Essays on reason and politics. Cambridge, MA: MIT Press; pp. 67-91.

Dryzek, J.S. 2010, "Rhetoric in democracy: A systemic appreciation", Political Theory, 38/3: 319-339.

Fredal, J. 2006, Rhetorical action in ancient Athens. Persuasive artistry from Solon to Demosthenes. Carbondale (IL): Southern Illinois University Press.

Garsten, B. 2011, "The rhetoric revival in political theory", Annual Review of Political Science, 14: 159-180.

Goodin, R.E. 2000, "Democratic deliberation within", Philosophy \& Public Affairs, 29/1: 81-109.

Lafont, C. 2006, “Is the ideal of a deliberative democracy coherent?", en S. Besson y J.L. Martí, eds. Deliberative democracy and its discontents. Aldershot, UK: Ashgate; pp. 3-26.

Landemore, H.E. 2012, "Why the many are smarter than the few and why it matters", Journal of Public Deliberation, 8/1, art. 7: 1-12 [http://services.bepress.com].

List, C. 2006, "The discursive dilemma and public reason", Ethics, 16: 362-402.

Nieuwenburg, P. 2004, "Learning to deliberate. Aristotle on truthfulness and public deliberation", Political Theory, 32/4: 449-467.

O'Neill, J. 2002, "The rhetoric of deliberation: some problems in Kantian theories of deliberative democracy", Res Publica, 8: 249-268.

Schmill, U. 1987, "El debate sobre Mitilene. Una interpretación”, Doxa, 4: 203-245. 
Sunstein, C. 2006, Infotopia: How many minds produce knowledge. Oxford/New York: Oxford University Press.

Timmerman, D.M. \& Schiappa, E. 2010, Classical Greek rhetorical theory and the disciplining of discourse. Cambridge, UK: Cambridge University Press

Vega Reñón, L. 2004, “Entimemas”, Doxa, 27: 283-315.

Yack, B. 2006, "Rhetoric and public reasoning: An Aristotelian understanding of political deliberation", Political Theory, 34/4: 417-438.

Young, I.M. 1996, "Communication and the other: beyond deliberative democracy", en S. Benhabib, ed. Democracy and difference, o.c., pp. 120-136. 